\title{
THE RELATION OF ENERGY AND MOTOR CAPACITY TO SCHEDULE SPEED IN THE MOVING \\ OF TRAINS BY ELECTRICITY.
}

BY CARY T. HUTCHINSON, PH.D.

The determination of the energy and power necessary to make a certain schedule speed from start to start under various conditions of initial accelerations, braking and use of the "motor curve" is a matter of much practical importance. A number of articles discussing special cases have been published. This paper gives a general solution of the question involved in the movement of a body from rest to rest with velocity varying as shown in Figs. 1 and 2-these two figures illustrating the practical problem of train acceleration. The solution here given covers all cases that can arise in ordinary practice of train movement. It affords a ready means of determining the energy, the power and the losses for any schedule speed, over a course of any length with any initial acceleration, tractive resistance or braking effort, and with any desired use of the " motor curve."

The solution is partly analytical and partly graphical; it may be divided into three stages: (1) The determination of the elements of Fig. 1 to give any schedule speed; this velocity-time $(v-t)$ curve I shall refer to as the "type curve." (2) The determination of a general tramway motor curve sheet and the deduction from this curve sheet of several dependent curves; and (3) The application of the general motor curves to the type curve of Fig. 1 to obtain a general solution of the $(v-t)$ curves of Fig. 2. Each case of Fig. 2 is reduced to a case of Fig. 1 by applying a 
correction to Fig. 2 , represented by the area $\mathrm{m} \mathrm{A} \mathrm{N}$, by which it is reduced to a corresponding case of Fig. 1.

Throughout the following units are used:

Velocity, in miles per hour (mph).

Acceleration, in miles per hour per second (mph./sec.

Distance, in feet (L).

Time, in seconds ( $t)$.

Weight, in pounds $(w)$.

Power, in kilowatts $(\mathrm{kw})$.

Energy, in watt-hours (wh).

These units are related as follows:

Miles per hour $(\mathrm{mph})=.0.682 \times$ feet per second.

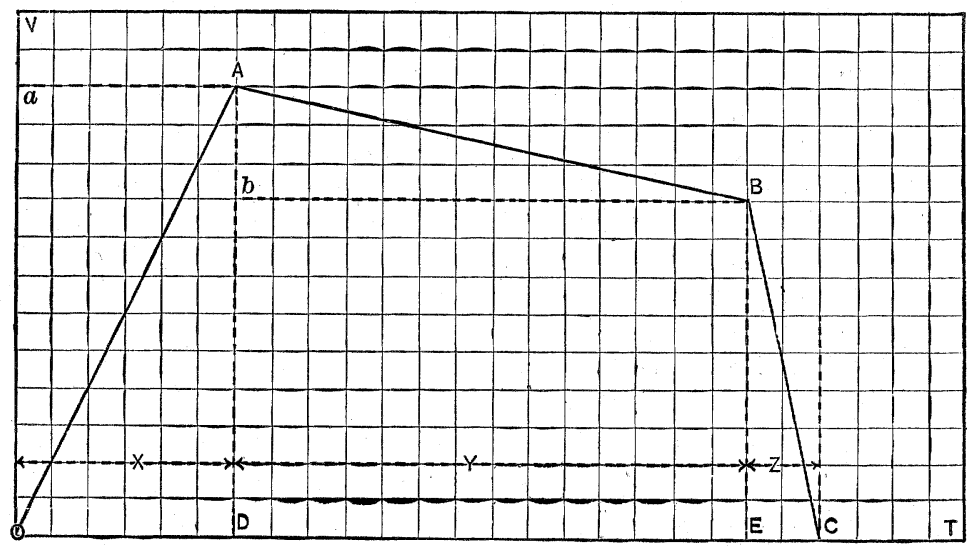

FIG. 1.

Miles per hour per second $(\mathrm{mph} . / \mathrm{sec}$.) $=0.682 \times$ feet per second per second.

Kilowatts $(\mathrm{kw})=.9.1 \times 10^{-5} \times \mathrm{w}(\mathrm{mph} . / \mathrm{sec}).(\mathrm{mph}$.

Watt-hours (wh.) $=1.25 \times 10^{-5} \times \mathrm{w}(\mathrm{mph} .)^{2}$ And, therefore,

Kilowatts per ton $(\mathrm{kw} . /$ ton $)=0.182 \times(\mathrm{mph} . / \mathrm{sec}).(\mathrm{mph}$.

Watt-hours per ton (wh./ton) $=2.5 \times 10^{-2} \times(\mathrm{mph} \text {. })^{2}$

In this system " $g$ " the acceleration of gravity is 22 ; the ton is uniformly $2,000 \mathrm{lbs}$.

Referring to Fig. 1, suppose a train to move at constant acceleration from rest to velocity $\mathrm{D} \mathrm{A}$ in time $\mathrm{O} \mathrm{D}$, then with constant retardation to velocity $\mathrm{E} B$ in time $\mathrm{D} \mathrm{E}$, and finally with constant 
retardation from $\mathrm{B}$ to $\mathrm{C}$ in time $\mathrm{E} \mathrm{C}$; the distances travelled in the time $\mathrm{O} D, D E$ and $\mathrm{E} C$ are represented by the areas $O \mathrm{AD}$, $\mathrm{D} A \mathrm{~B} E$ and $\mathrm{E} \mathrm{D}$ C, respectively, the acceleration by the inclination of the lines to the horizontal.

Let

$$
\begin{aligned}
& a=\text { Acceleration along } \mathrm{OA}=\mathrm{D} \mathrm{A} / \mathrm{O} \mathrm{D} . \\
& b=\text { Retardation along } \mathrm{A} \mathrm{B}=\mathrm{A} \mathrm{D} / \mathrm{E} \\
& c=\text { Retardation along } \mathrm{B} \mathrm{C}=\mathrm{B} \mathrm{E} / \mathrm{E} \mathrm{C} . \\
& x=\text { Time for } \mathrm{OA}=\mathrm{O} \mathrm{D} \\
& y=\text { Time for } \mathrm{A} \mathrm{B}=\mathrm{DE} \\
& z=\text { Time for } \mathrm{B} \mathrm{C}=\mathrm{E} \mathrm{C}
\end{aligned}
$$

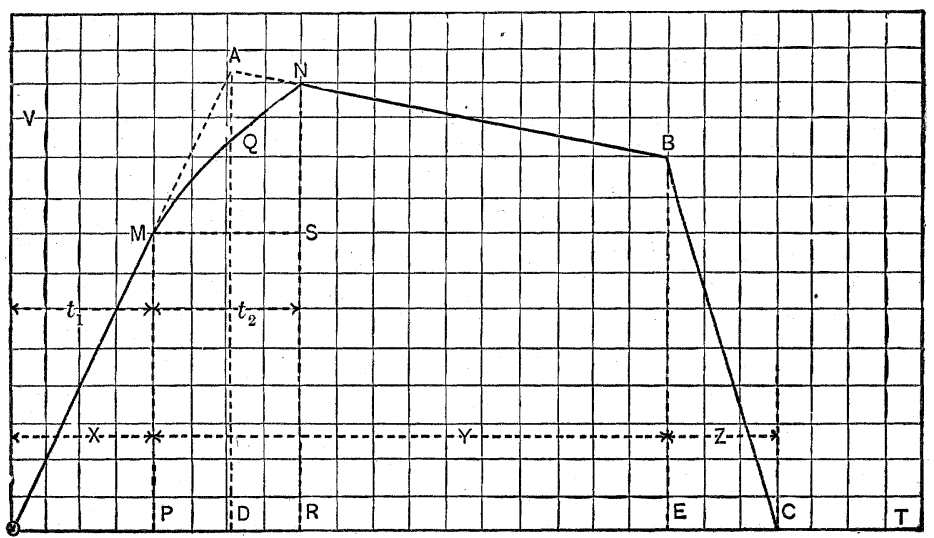

FIG. 2 .

$$
\begin{aligned}
& s_{1}=\text { Distance for } \mathrm{O} \mathrm{A}=\text { Area } \mathrm{OA} \mathrm{D} \\
& s_{2}=\text { Distance for } \mathrm{A} \mathrm{B}=\text { Area } \mathrm{D} \mathrm{A} \mathrm{B} \mathrm{E} \\
& s_{3}=\text { Distance for } \mathrm{B} \mathrm{C}=\text { Area } \mathrm{E} \mathrm{B} \mathrm{C} \\
& T=\text { Total time }=\text { o C } \\
& L=\text { Total distance }=\text { Area o A B C } \\
& V=\text { Average velocity }=.682 \mathrm{~L} / \mathrm{T}
\end{aligned}
$$

Then these three equations hold:

Velocities: $a x-b y-c z=0$

Times: $\quad x+y+z=T$

Distances: $a x^{2}-b y^{2}+c z^{2}+2 a x y=2 \times .682 L$ 
The work of solving these equations is tedious; I shall give only the results and in a simplified form:

Put

$$
\begin{aligned}
& A=V / T=.682 L / T^{2}=1.47 V^{2} / L \\
& 2 A_{0}=a c /(a+c) \\
& 2 M=(a+b)(a+c)(c-b) \\
& K_{1}=(c-b) / M^{1 / 2} \\
& K_{2}=(a+c) / M^{1 / 2} \\
& K_{3}=(a+b) / M^{1 / 3}
\end{aligned}
$$

Where

Then will

$$
K_{1}+K_{2}+K_{3}=0
$$

$$
\begin{aligned}
& x / T=2 A_{0} / a-K_{1}\left(A_{0}-A\right)^{1 / 2} \\
& y / T=K_{2}\left(A_{0}-A\right)^{1 / 2} \\
& z / T=2 A_{0} / c-K_{3}\left(A_{0}-A\right)^{1 / 2}
\end{aligned}
$$

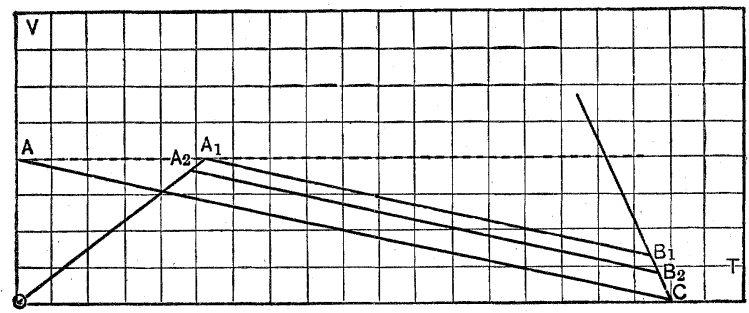

FIG. 3.

And

$$
\begin{aligned}
& a x / T=2 A_{0}-a K_{1}\left(A_{0}-A\right)^{1 / 2} \\
& b y / T=\quad b K_{2}\left(A_{0}-A\right)^{1 / 2} \\
& c z / T=2 A_{0}-c K_{3}\left(A_{0}-A\right)^{1 / 2}
\end{aligned}
$$

These three equations are the general solution of the problem in kinematics illustrated in Fig. 1; that is, the motion of a particle from rest to rest, with three different accelerations. The only term in the equations containing the average velocity or the length is $A$; all the other terms are functions of the three accelerations. This quantity $A$ then determines completely the schedule. All schedules having the same value of $A$ will be accomplished by the same accelerations in the same proportional times; that is, the same fraction of the total time will be occupied 
in the three phases of the movement. This quantity is then the independent variable and is of utmost importance in this discussion; it deserves a specific name, and for want of a better I shall call it the "Through acceleration," and denote it by $A$. All schedules with the same "through acceleration" but with different $V$ and $T$, are represented by similar figures-the scale only being different.

These equations show that the maximum through acceleration for given values of $(a),(b)$ and $(c)$ is equal to $A_{0}$, and that this will occur when $y=0$; that is, when there is no retardation along A $\mathrm{B}$, or, in electric parlance, " no coasting."

Three special conditions of importance are readily determined:

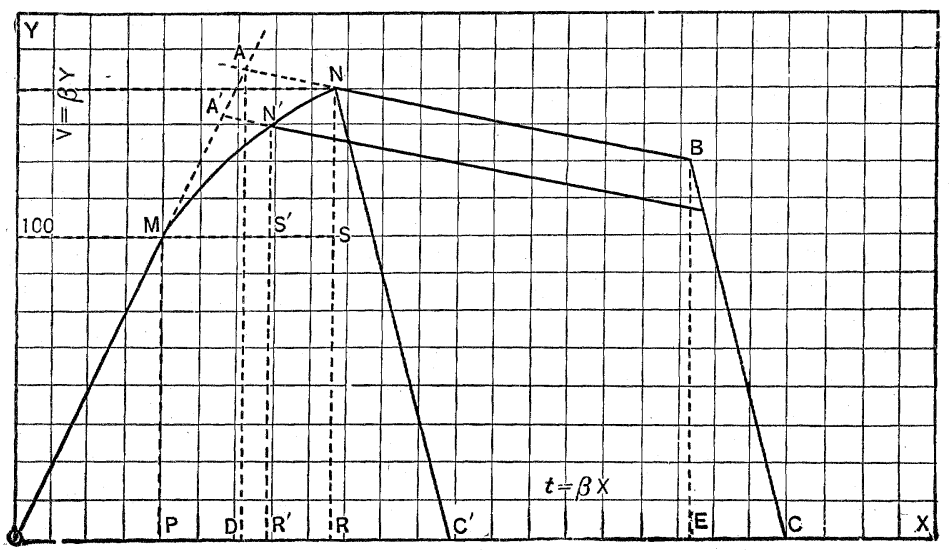

FIG. 4.

(1) Infinite acceleration, $a=\infty$

$$
\begin{gathered}
x / T=0 \\
y / T=\left(\frac{c-2 A}{c-b}\right)^{1 / 2} \\
z / T=1-\left(\frac{c-2 A}{c-b}\right)^{1 / 2}
\end{gathered}
$$

and

(2) No coasting, $y=0$

$$
a x / T=c-(c-b)^{1 / 2}(c-2 A)^{1 / 2}
$$

$$
A_{0}=A=a c / 2(a+c)
$$




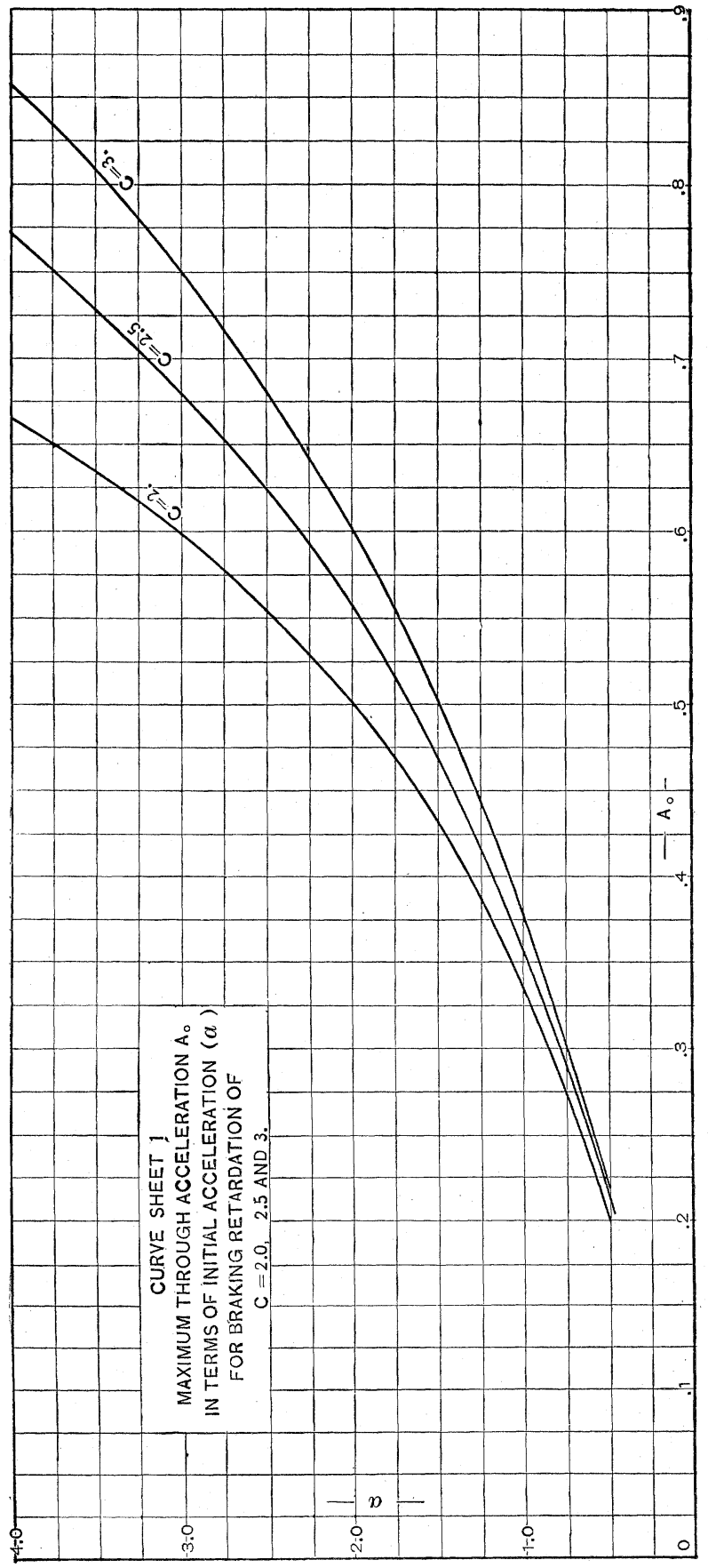


(3) No braking, $z=0$

$$
\begin{aligned}
& a b / 2(a+b)=A \\
& x / T=b /(a+b)
\end{aligned}
$$

Equation (15) determines the maximum through acceleration, and equation (16) the minimum through acceleration; all possible values lie between these two.

Equation (14) gives the maximum velocity for infinite initial acceleration; this is the least maximum velocity for any value of $A$ greater than $b / 2$. For values of $A$ less than $b / 2$ the maximum velocity for infinite acceleration is the greatest possible maximum. This seems abnormal, but that it is correct can be seen readily from Fig. 3 , where $\mathrm{O} \mathrm{A} \mathrm{C}$ shows the curve for $A=$ $b / 2$ and $a=\infty$. Since $\mathrm{A}$ is represented by the area of the triangle $O \mathrm{~A} \mathrm{C}$; it is clear that for an acceleration $O \mathrm{~A}_{2} \mathrm{~A}_{1}$ the area o $A_{1} B_{1} C$ is greater than $O A C$, and that at some point $A_{2}$ the area $\mathrm{O} \mathrm{A}_{2} \mathrm{~B}_{2} \mathrm{C}$ will be equal to $\mathrm{OA}$ C. That is, when the schedule is slow, the maximum velocity increases with the initial acceleration.

The relations of these quantities are best shown graphically; they are plotted in various ways on the curve sheets described.

Curve sheet 1 is plotted from equation (15), and shows $\mathrm{A}_{0}$ in terms of $(a)$ for $b=.2$, and for $c=2,2.5$ and 3 . These are the maximum values of the through acceleration $\mathrm{A}$ in terms of $(a)$ for the several values of $(c)$. They show the influence of $(c)$, the retardation after braking, on $\mathrm{A}_{0}$.

Curve sheet 2 is plotted from equations (6), (7) and (8), and gives the values of $x / T, y / T$ and $z / T$ in terms of $A$ for different values of $(a)$ varying from .25 to 3.0 , and for $a=\infty$; for $b=.2$, and $c=3$.

The values of $x / T$ are the intercepts between the $X$ axis and the branch of the $a$ curve lying below the line $\mathrm{A}$ B; the values of $y / T$ are included between the two branches of the $a$ curve, and of $z / I$ are included between the line $\mathrm{A} D$ and the upper branch of the $a=$ curve.

For instance, for $A=.4, a=1.5, x / T=\mathrm{M} \mathrm{N}, y / T=\mathrm{NP}$, $z / T=\mathrm{P}$ Q. The line $a=\infty$ is the axis of $X$; the line $\mathrm{A}$ B is the locus of $y=0$ or of "no coasting," and the intersection of the $a$-curves with this gives the maximum through acceleration for that value of $(a)$. The line $\mathrm{A} \mathrm{C}$ is the line of no braking, and its intersection with the $a$-curves gives the minimum values of $A$ 


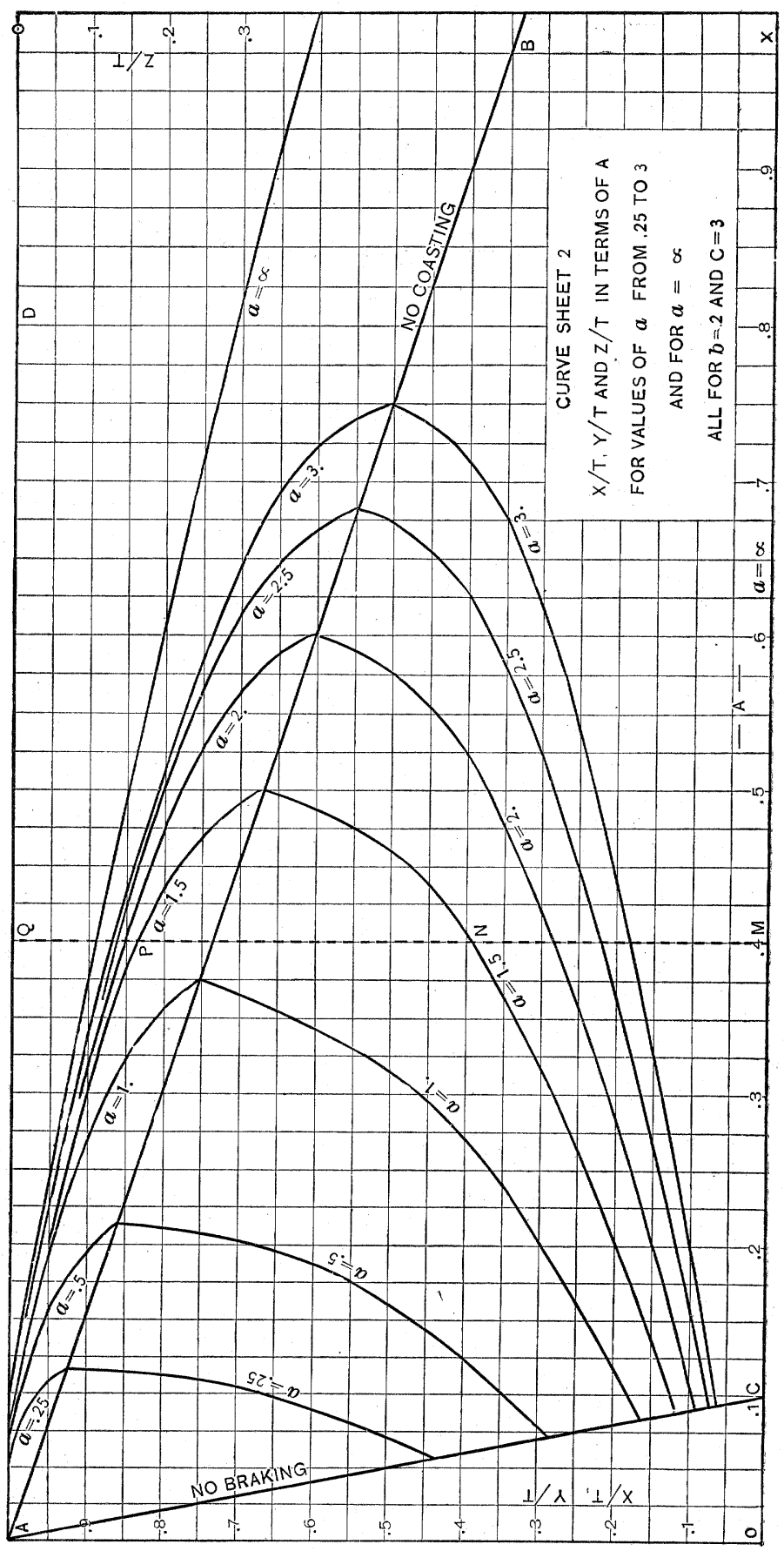


These curves give all possible values of $A$, and enable Fig. 1 for any particular case to be drawn at once.

Curve sheet 3 is plotted from equation (9), and gives $a x / T$ in terms of $A$ for different values of $(a)$, and for $b=.2, c=3$. These curves show at a glance the variation of maximum velocity with different initial acceleration, and the crossing of the $a$-curves.

Curve sheet 4 shows $a x / T$ in terms of $A$ for $b=.2$ and for $c=2.0$. It illustrates the influence of the braking effort on the maximum velocities.

These curve sheets give a complete determination of the kinematics of the problem. There remains the determination of energy and power - the kinetics. I limit the discussion to the case in which power is applied along o A (Fig. 1) only, and the car is allowed to " coast" with gradually diminishing velocity due to the constant retardation $(b)$ from $A$ to $B$, where a braking force producing a retardation $(c-b)$ is applied, making a total retardation equal to $(c)$.

The assumption of $(b)$ constant is necessary to a simple discussion; if it is not so, an average value may be used-considerable variations in the value of $(b)$ make little difference. I use throughout $b=.2 \mathrm{M}$. P.H. $/ \mathrm{sec}$, equal to a force $18.2 \mathrm{lbs}$. per ton; (b) represents the total tractive resistance on a level at uniform speed, and with electric motors, includes motor friction.

The force exerted along o A (Fig. 1) is

$$
f=\frac{w}{g}(a+b), 1 \mathrm{bs}
$$

and the total energy input at the car axle, per ton, up to the point $A$ is

Of this energy

$$
2.50 \times 10^{-2}(1+b / a) \overline{a x^{2}}, \text { wh }
$$

$$
2.5 \times 10^{-2} \times \overline{a x^{2}}, \text { wh }
$$

is represented by the kinetic energy at point $A$, and

$$
2.5 \times 10^{--2} \overline{a x^{2}} \times b / a, \text { wh }
$$

is the work done in overcoming tractive resistances up to point $A$.

The power per ton is

$$
P=0.182(a+b) a x, \mathrm{kw}
$$

Schedule Speed.-The relation of schedule speed $S$ to average 
velocity $V$ is dependent upon the time of stops at the station. If $t$ is the time of stop at station, then

$$
\begin{aligned}
T & =.682 \mathrm{~L} / \mathrm{S}-t \\
V & =.682 \mathrm{~L} / T \\
A & =V / T=1.47 \mathrm{~V}^{2} / L
\end{aligned}
$$

These equations give $A$ in terms of $S$ and $L$. If $t$ is taken at

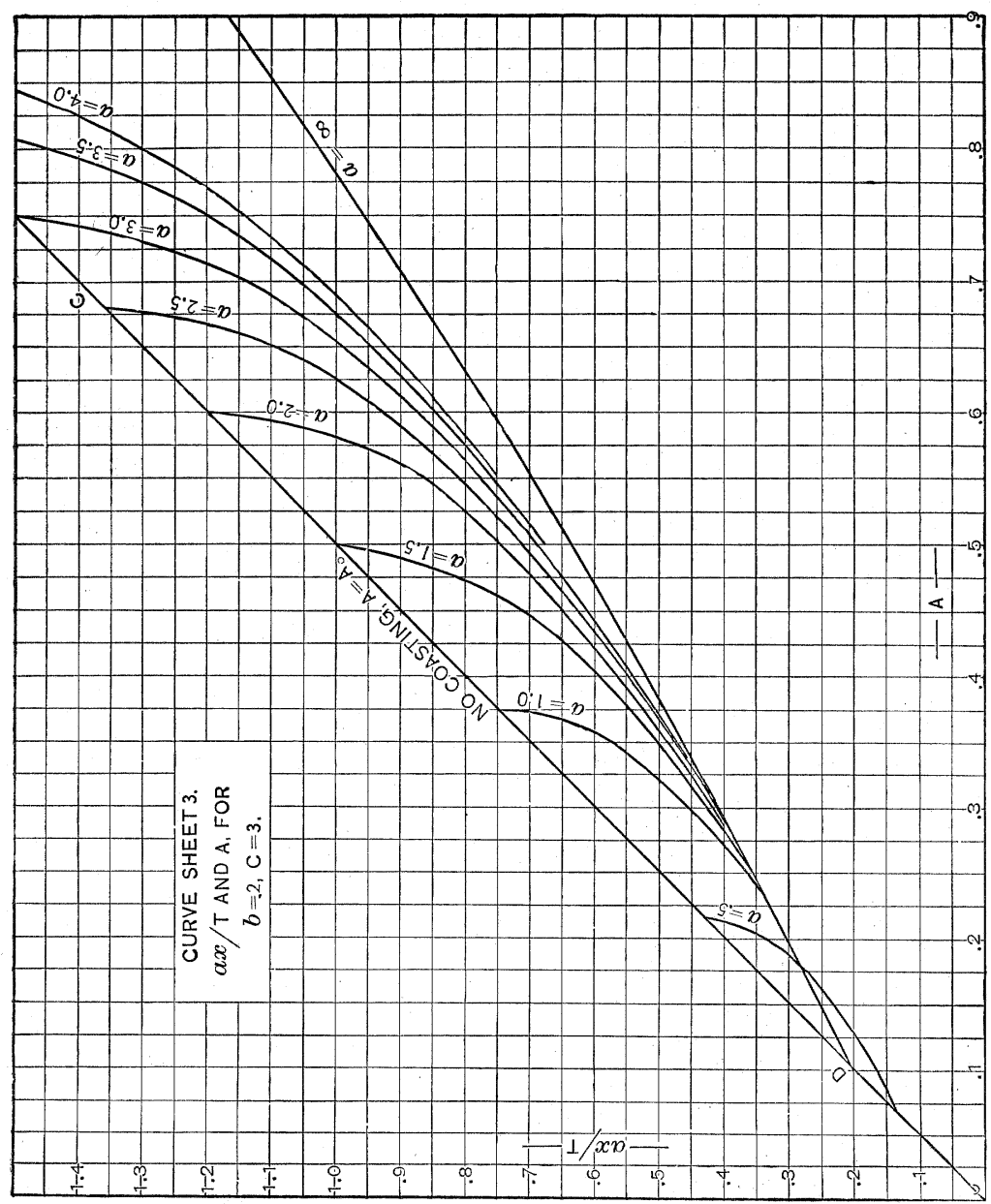

any constant value, curves can be plotted giving $V$ in terms of $S$ and $L ;$ it is, however, simpler to use the equations.

I do not consider the schedule speed further, but assume $V$ and $T$ to be determined from $S,(t)$ and $L$. Knowing $A$, curve sheet 2 gives $x / T$ and hence $(a x)$ for any values of $A$. The energy and power are then determined by equations (17) and (18). 
These quantities refer to the car axle and do not include losses of any kind in the motor, and hence are of theoretical interest only. If motors had constant efficiency, these values would be proportional to the energy input.

The discussion to this point is applicable to any kind of motive power. The matter of practical interest is the application to

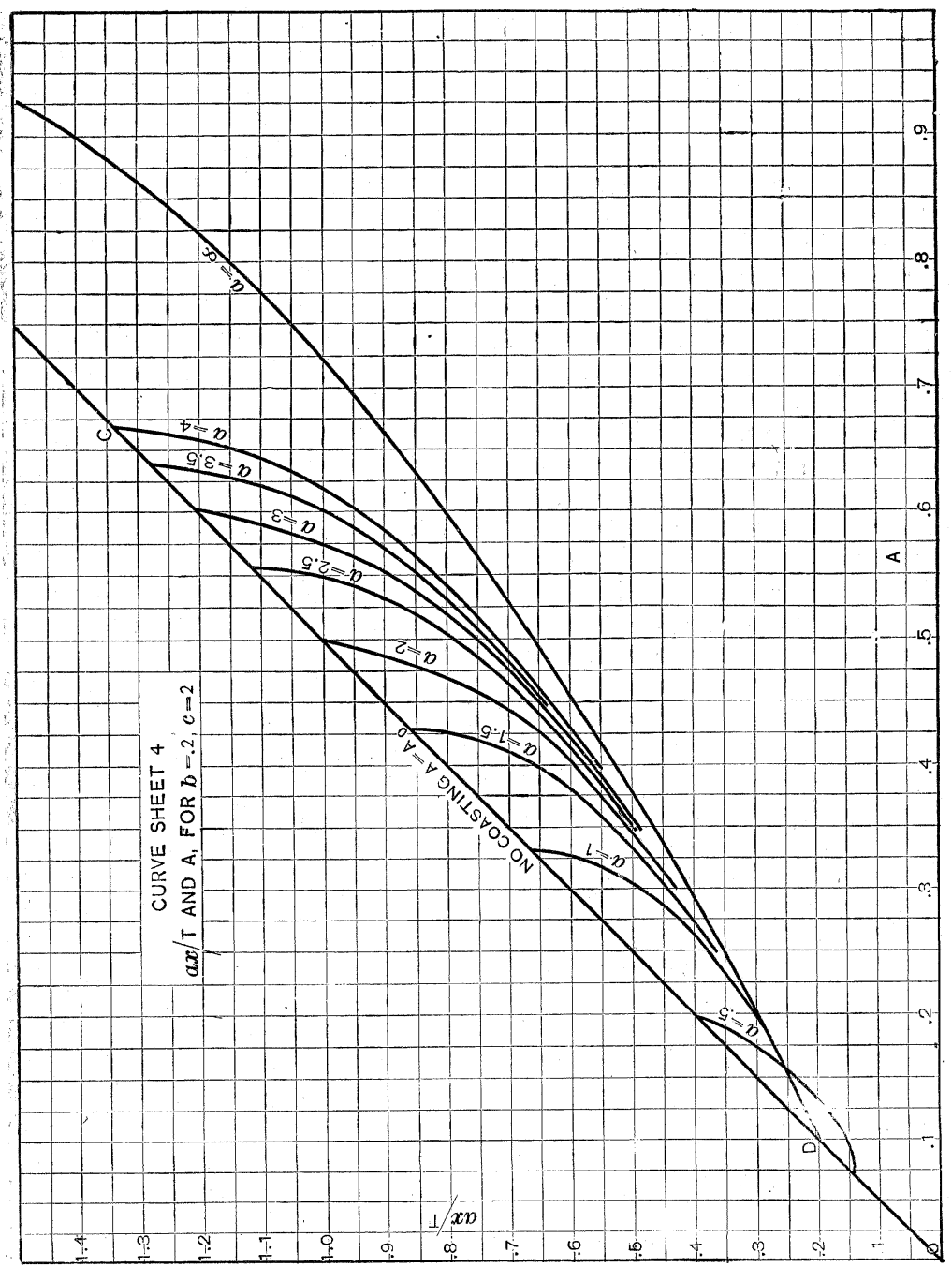

electric motors, and the determination of the quantities for the $(v-t)$ curve of Fig. 2; the characteristics of the motor must be taken into account.

General Motor Curves.-In order to make the discussion general, it is not sufficient to consider one or two sizes of motor or 
one or two gearing ratios-all sizes and all gear ratios must be included, or what is the same thing, all values of torque at the axle and all values of velocity; in a word, a set of motor curves applicable to all sizes of motors must be prepared.

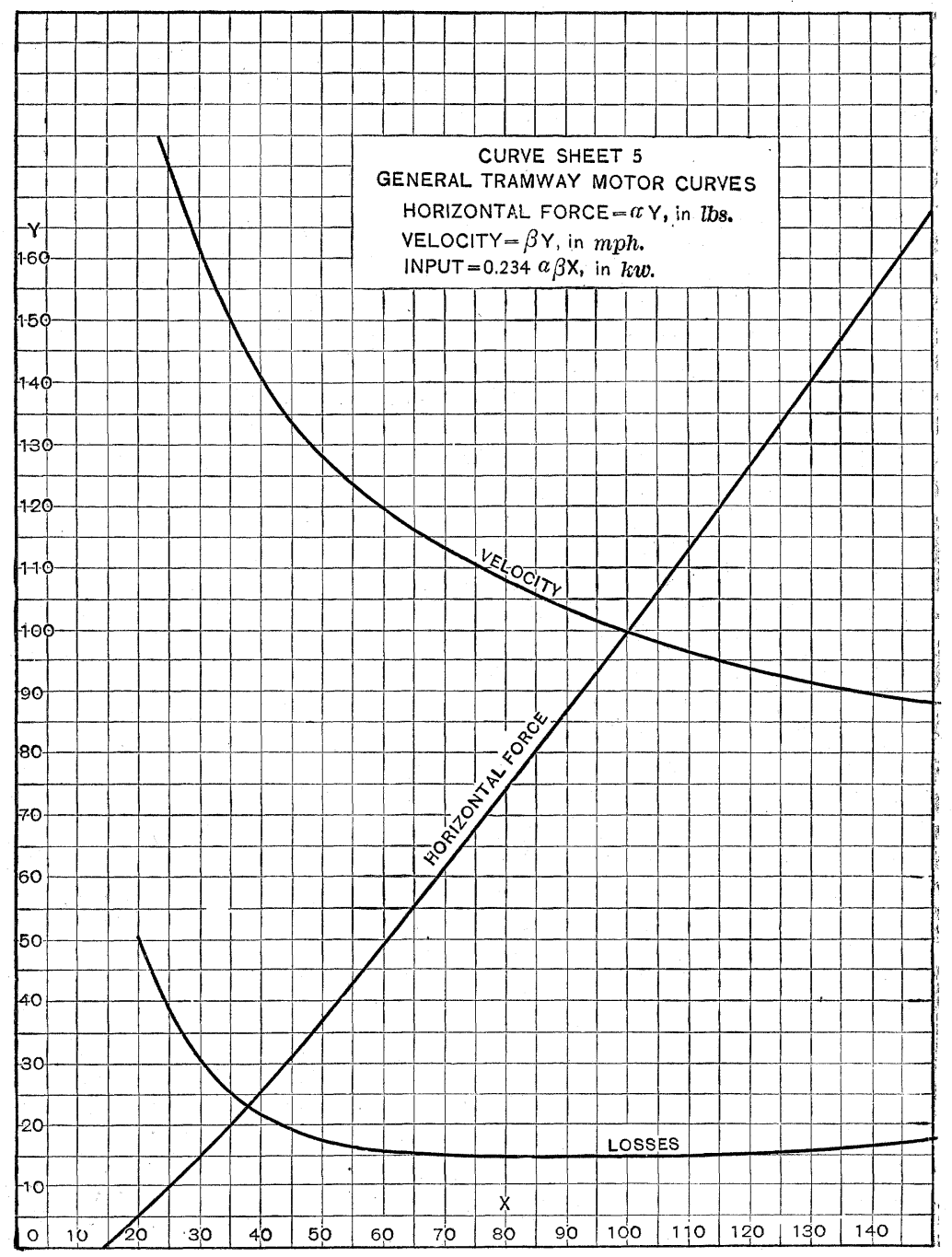

I have plotted the values of torque and speed in terms of input for some twenty tramway motors of different sizes and makes, expressing all quantities in percentage of their value at rated load, and find that the agreement is close-so close that one set of curves can with sufficient exactness for this purpose be used 
for almost any modern tramway motor built in the United States. It is immaterial whether this general motor curve represents any particular motor. By using this curve, the identically same characteristics are retained for all initial accelerations, hence the use of such a curve brings out the differences due to the different initial accelerations without complicating them by the differences in individual motor characteristics. Curve sheet 5 is this general tramway motor curve; abscissæ are input in kilowatts; ordinates are horizontal force $(f)$ in $1 \mathrm{bs}$., and speed $(v)$ in miles per hour; on these curves the rated load is the point $(100,100)$ and is the rating on a one-hour basis, heating to $75^{\circ} \mathrm{C}$.- the common tramway motor rating. Losses also are plotted; they differ much more in various motors than do $(f)$ and $(v)$.

Let $\beta Y^{\prime}$ be the velocity and $\alpha Y^{\prime \prime}$ the horizontal force, then every variation in conditions can be met by giving suitable values to $\alpha$ and $\beta$; this use of horizontal force and linear velocity eliminates the gearing ratio and size of wheel, both of which are determined by considerations outside of this discussion. Then for any value of $X$,

$$
f=\alpha Y^{\prime \prime}, 1 \mathrm{bs} .
$$

The output is

$$
\text { and } v=\beta Y^{\prime}, \mathrm{mph} \text {. }
$$

$$
\left[a \beta Y^{\prime} Y^{\prime \prime}\right] / 503, \mathrm{kw} \text {. }
$$

and the input is

$$
\left[\alpha \beta Y^{\prime} Y^{\prime \prime}\right] /(e \times 503), \mathrm{kw} \text {. }
$$

where $e$ is the efficiency at the point $\left(X, Y^{\prime}, Y^{\prime \prime}\right)$ taken from the motor curve sheet. Choosing the point $(100,100,100)$, the rated load, then $e=.85$, and the input is

$$
P=0.234 \alpha \beta X, \mathrm{kw} \text {. }
$$

This determines the constant multiplier for the input in terms of $\alpha$ and $\beta$.

An example will make the use of these curves clear; suppose a motor is to exert a horizontal force of $2,000 \mathrm{lbs}$. at a speed of $20 \mathrm{mph}$; if this is required at the rated load, then

and

$$
\begin{aligned}
& a=20, \quad \beta=.2 \\
& P=0.936 X, \mathrm{kw} .
\end{aligned}
$$

at rated load this motor is $93.6 \mathrm{kw}$.

It is not necessary to choose the point of rated load, any other point could be taken; for instance, a motor may be assumed to give $2,000 \mathrm{lbs}$. at $125 \%$ torque and $30 \mathrm{mph}$. at the corresponding value of the velocity, which is $93.8 \%$; the motor is then carrying a load of $119 \%$. 


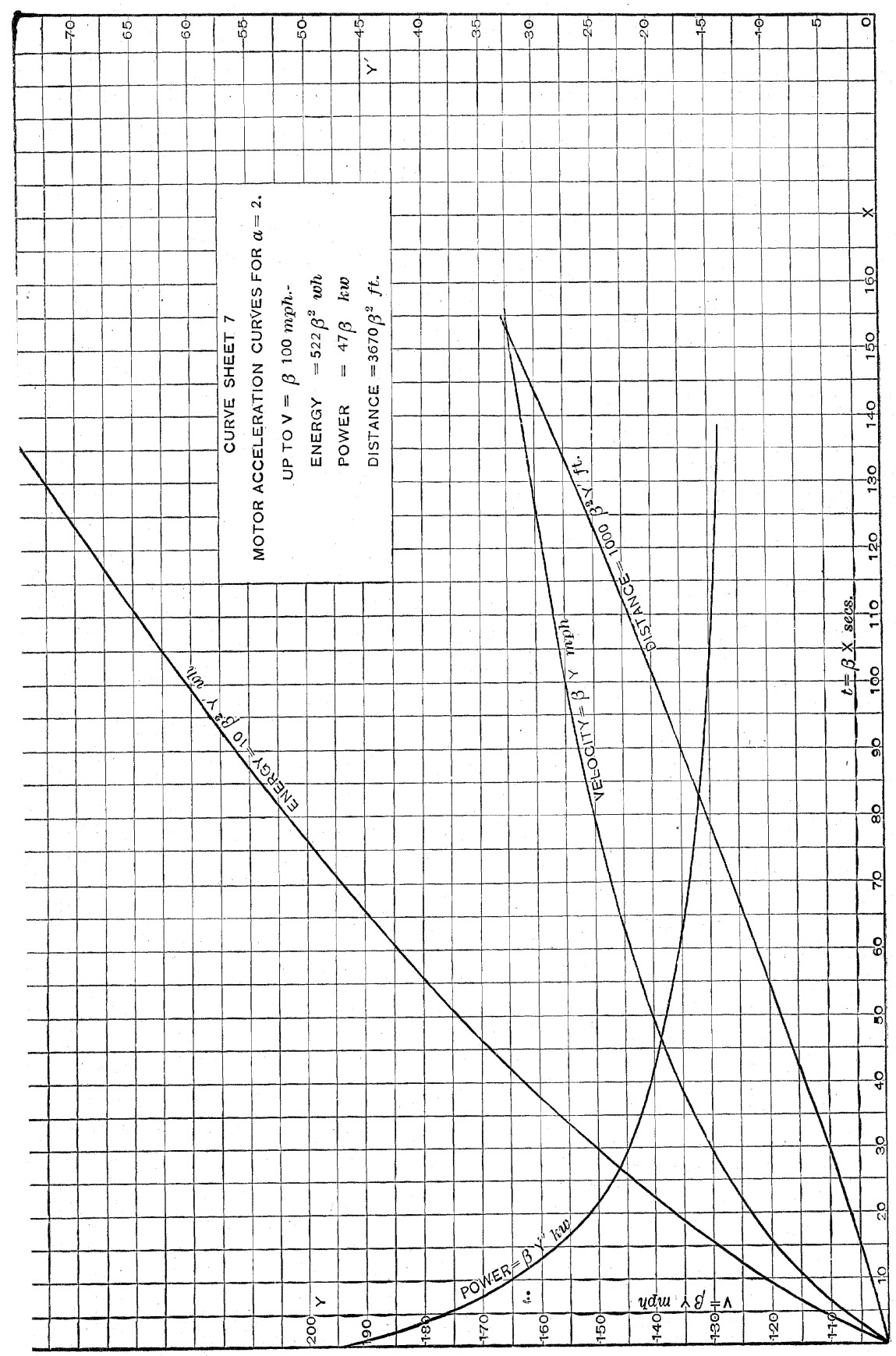


The gear ratio, size of wheel and motor capacity must be mutually adjusted to give the required force and velocity at the chosen point of motor input.

I assume in what follows that $\propto$ and $\beta$ are chosen for rated load; this matter is discussed further under the head of motor rating.

Acceleration Curves.- $\mathrm{M}$ (Fig. 2) is the point where the external resistance is all out of the circuit, and the motors begin to run on the " motor curve." The force exerted along o $\mathrm{m}$ is proportional to $(a+b)$. Assume this force to be the rated force of the motor and represented by the point $Y^{\prime \prime}=100$ on the general motor curve. The velocity at $M$ is the rated velocity, is represented by $Y^{\prime}=100$, and is equal to $\beta 100 \mathrm{mph}$. The acceleration on the motor curve continues to a point $\mathrm{N}$, where the velocity is $\beta Y^{\prime}, Y^{\prime}$ having any desired value greater than 100 . The shape of the curve $\mathrm{M} Q \mathrm{~N}$ depends on the relative values of $(a)$ and $(b)$. If $a / b$ is large, the curve is steep; if small, flat. This curve is determined as follows:

The force at any point on the curve, as $Q$, is

$$
\text { Force }=\frac{w}{g}[d v / d t+b]=\alpha Y^{\prime \prime}
$$

where $Y^{\prime \prime}$ is the ordinate of the $(f)$ curve of sheet 5. For $Y^{\prime \prime}=$ 100 at rated load and point $\mathrm{m}$,

hence

$$
d v / d t=a
$$

$$
a=\frac{W}{g} \times \frac{(a+b)}{100}
$$

and

$$
d v / d t=\frac{(a+b)}{100} Y^{\prime \prime}-b
$$

But

and hence

$$
\begin{aligned}
& d v / d t=\beta\left[d Y^{\prime} / d t\right]=\beta\left[\Delta Y^{\prime} / \Delta t\right] \\
& \Delta t / \beta=\Delta Y^{\prime} /\left[(a+b) Y^{\prime \prime} / 100-b\right]
\end{aligned}
$$

From this equation, $\Delta t / \beta$ can be calculated for different values of $(a)$ and $(b)$, by taking from the velocity curve of sheet $5 \Delta Y^{\prime}$, and the corresponding values of $Y^{\prime \prime}$, the average force ordinate for the interval, $\Delta Y^{\prime}$. Other methods may be used to calculate: this tangent curve.

The values of $\Delta t / \beta$ are calculated and summed up. Plotting these values as abscissæ in terms of velocity as ordinates, a set 


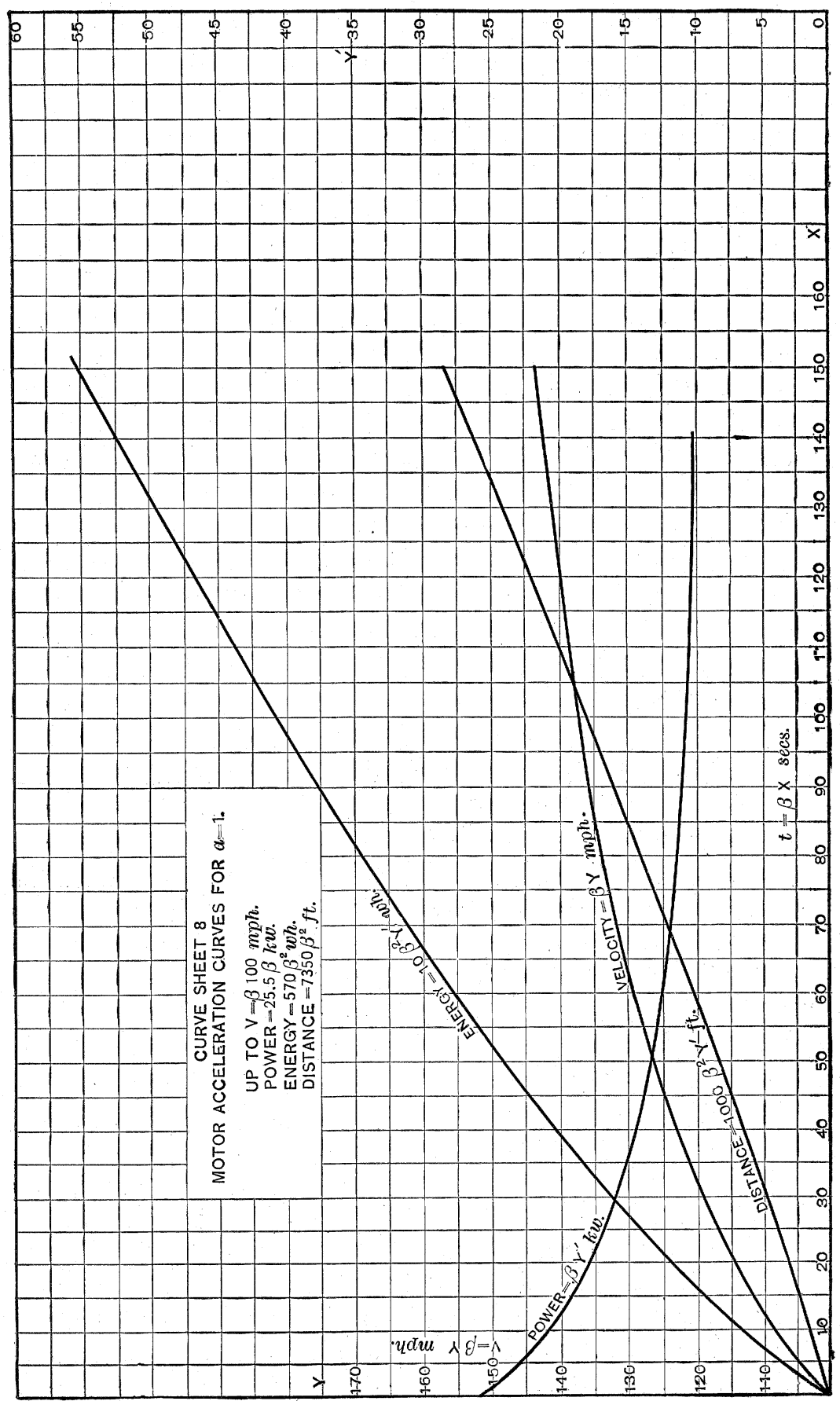


of curves is obtained for each value of $(a)$ which I call the acceleration or $(v-t)$ curve of the motor. The input corresponding to each velocity can be plotted on the same sheet, forming a ( $\mathrm{kw}$.time) curve, and from the last by integration, an energy curve. Also from the $(v-t)$ curve, by integration, a curve of distance and time can be plotted. This gives a set of curves for each value of the initial acceleration, showing at once the power, energy, velocity and distance up to any relative velocity on the motor curve.

The deduction of these curves and their constants is as follcws: From (19) and (21) and for $w=2,000 \mathrm{lbs}$.

$$
\text { Power. }-P=0.213(a+b) \beta \times X, \mathrm{kw} \text {. } / \text { ton }
$$

where $X$ is the abscissa, taken from curve sheet 5 for any ve1ocity.

Energy.-Similarly,

$$
W=\frac{1000}{3600} \int_{v=\beta 100}^{v=\beta Y} P d t, \quad \text { wh./ton }
$$

and substituting from (23)

$$
W=5.92 \times 10^{-2}(a+b) \int_{100}^{I} Y d X, \quad \text { wh./ton }
$$

$Y$ and $X$ are the co-ordinates of $P$ on the several acceleration sheets.

Distance.-

$S=1.467 \int v d t=1.467 \beta^{2} \int_{100}^{Y} Y d X$

where $Y$ and $X$ are the co-ordinates of $(v)$ on the several acceieration sheets.

Curve sheet 6 is calculated and plotted from equations 22,23 , 24 and 25 , for $(a)=3$. It shows velocity, distance, power and energy per ton in terms of time; the curves all start at $v=\beta 100$; that is, the energy and distance are for the motor curves, and do not include energy and distance up to velocity $v=\beta 100$.

Curve sheets 7,8 and 9 give the same quantities for $(a)=2$ 1 , and 0.5 respectively. 


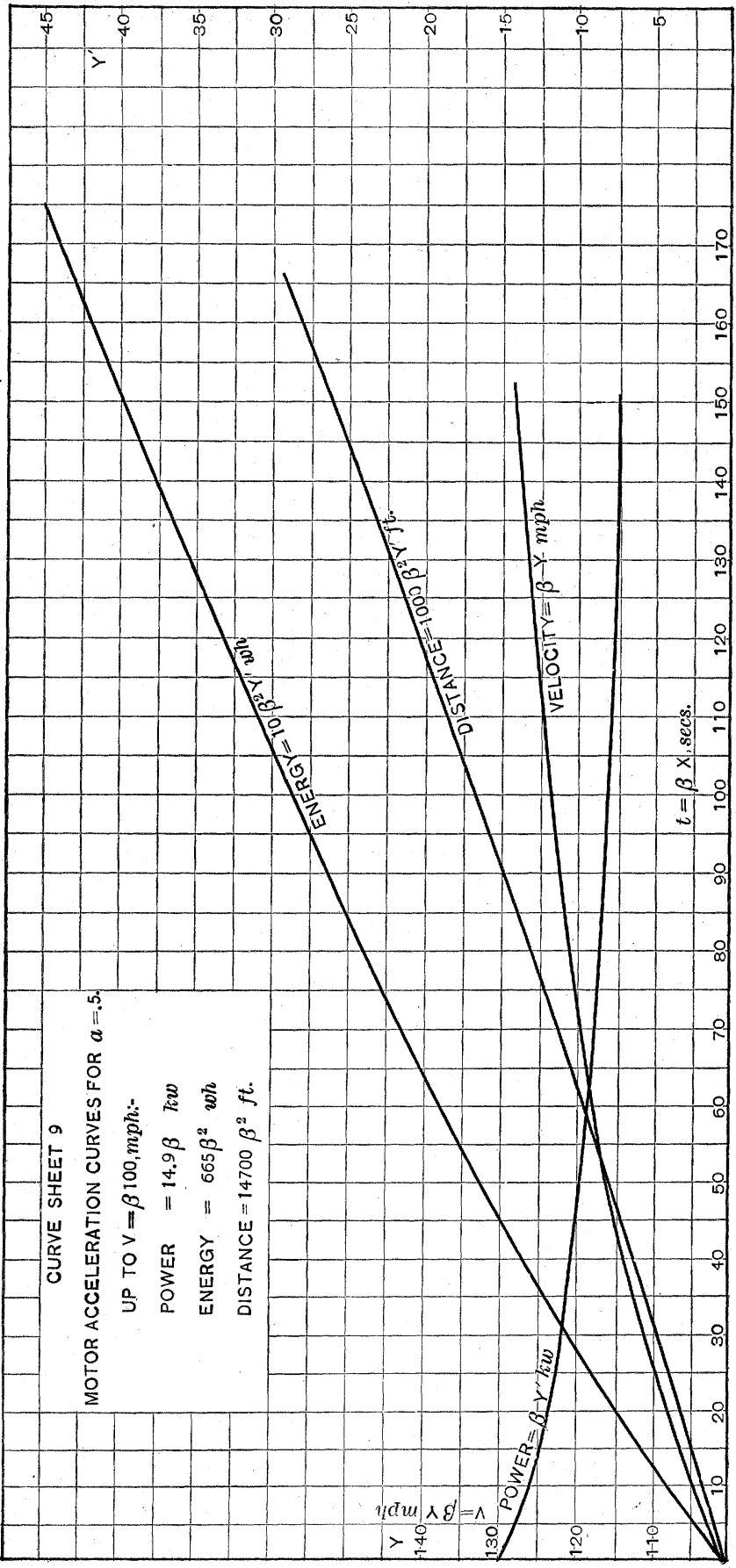


The coefficient $\alpha$ has disappeared Irom these curves, only $\beta$, the velocity coefficient, remains. Power and velocity are proportional to $\beta$; energy and distance to $\beta^{2}$.

As an example of the use of these curves, take $a=3$, curve sheet 6 . For a motor to have a rated velocity of $20 \mathrm{mph} ., \beta=$ 0.2 ; after a time $X=70 \beta=14$ seconds, the velocity will be $159 \beta=31.8 \mathrm{mph}$; the power $21.0 \times \beta=4.20 \mathrm{kw}$; the energy used on the motor curve $-590 \beta^{2}=23.6$ wh., and the distance traversed on the motor curve, $14,250 \times \beta^{2}=570$ feet.

From these $(v-t)$ curves, Fig. 4 is drawn, on which the line o $\mathrm{m}$ represents the initial acceleration continued to the velocity $v=$ $\beta 100$, where the acceleration on the motor curve begins and continues to any point $\mathrm{N}$; the velocity $\mathrm{R} \mathrm{N}$ is made anything within practical conditions; coasting begins at $\mathrm{N}$ and continues to $\mathrm{B}$, where brakes are applied. The ordinates multiplied by $\beta$ give the velocity, the abscissæ multiplied by $\beta$ give the time; hence, the inclination of any line on this diagram is independent of $\beta$.

Correction to Type Curve:-This discussion and the curve sheets deduced from it, determine all the elements of the type curve, O A B C. This type curve bears a certain relation to the motor curve $о$ м N в C. The distance traversed in the first case will be greater than in the second by the equivalent of the area $\mathrm{M} \mathrm{A} \mathrm{N}$. It is then possible to reduce each case for the motor curve to a corresponding case for the type curve by applying a correction, calculated in the following manner:

Determine the area M A N of Fig. 4 for each $(a)$, and for any desired number of points on the motor curve; call this area $\Delta$; then $1.47 \beta^{2} \Delta$ is the distance in feet represented by the area.

Let

$Y_{\mathrm{t}}$ be the maximum velocity A $\mathrm{D}$ on the type curve;

$Y_{\mathrm{m}}$ be the maximum velocity $\mathrm{R} \mathrm{N}$ on the motor curve;

$A$ be the through acceleration on the type curve:

$A_{\mathrm{m}}$ be the through acceleration on the motor curve; and

$X$ be $\overline{\mathrm{oc}}$;

Then

or

$$
\begin{aligned}
& L=L^{\prime}-1.47 \beta^{2} \Delta \\
& \beta^{2} A_{\mathrm{m}} X^{2}=\beta^{2} A X^{2}-\beta^{2} \Delta
\end{aligned}
$$$$
A_{\mathrm{m}}=A-\Delta / X
$$ 
Put

then

$$
\lambda=a x / T=Y_{\mathrm{t}} / X
$$

$$
A_{\mathbf{m}}=A-\Delta\left(\lambda / Y_{\mathrm{t}}\right)^{2}
$$

$Y_{\mathrm{t}}$ is found from curve sheets 6 , et seq., and $\lambda$ from curve sheet 2 , for any values of $A,(a)$ and $Y_{\mathrm{m}} ; A_{\mathrm{m}}$ is then calculated, and plotted in terms of $A$, using the values of $\Delta$ previously calculated.

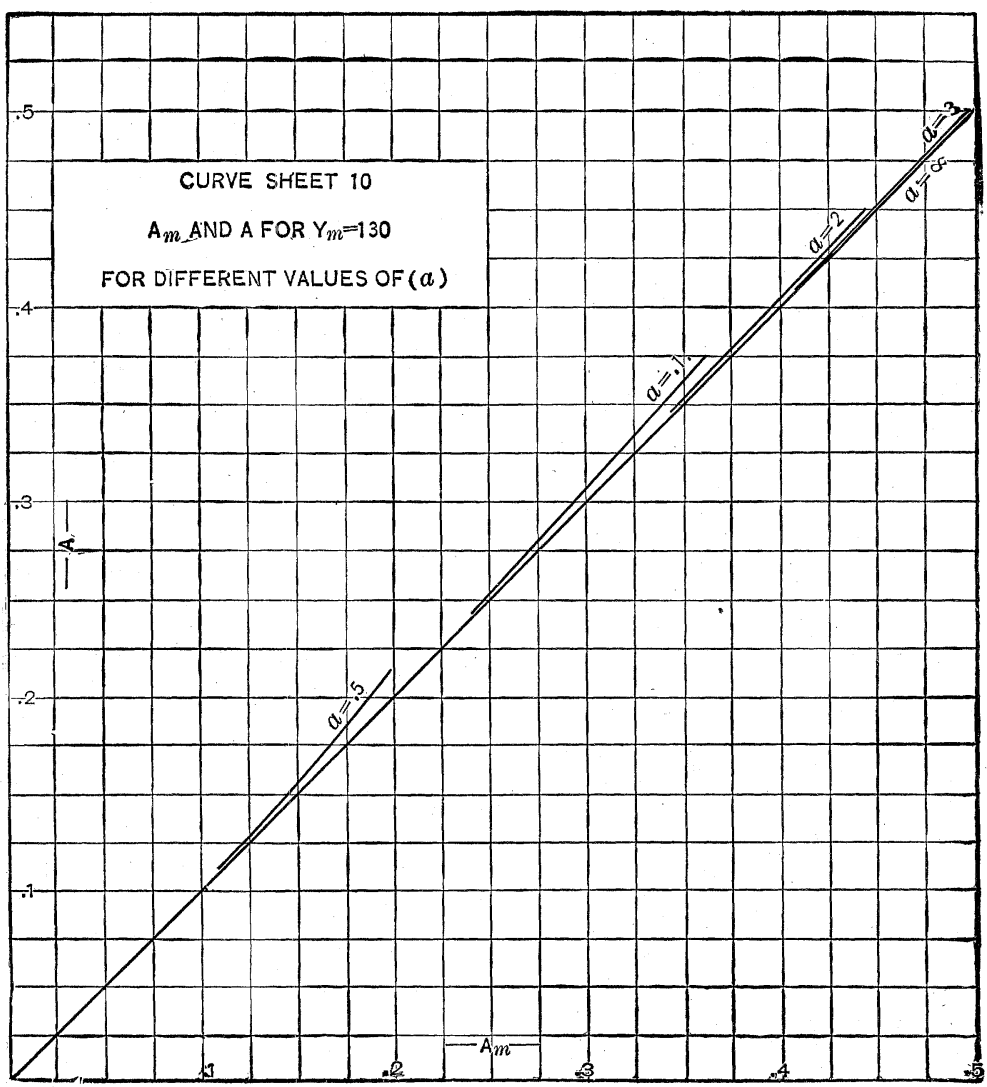

The values of $A_{\mathrm{m}}$ for all values of $A, Y_{\mathrm{m}}$ and $(a)$, have been determined in this way; the corrections for values of $Y_{\mathrm{m}}$ less than 130 are too small to be taken into account; as I shall show, the minimum energy required for all schedules and for all values of (a), is practically at $Y_{\mathbf{m}}=130$; in some cases greater values of $Y_{\mathrm{m}}$ give slightly less energy, but the difference is so trifling that I have used only this value in discussing the energy relations. 
Curve sheet 10 shows $A_{\mathrm{m}}$ in terms of $A$, for $Y_{\mathbf{m}}=130$, and for the different values of $(a)$.

Maximum $A_{\mathrm{m}}$ :-The maximum $A_{\mathrm{m}}$ is evidently attained when acceleration is continued to the braking point and is represented by $\mathrm{O} \mathrm{M} \mathrm{N} \mathrm{C'}$ (Fig. 4). To calculate this maximum, o R is found from curve sheet 6 et seq., $\mathrm{R} \mathrm{C}^{\prime}$ from the known values of $\mathrm{R} \mathrm{N}$ and $(c)$; - then $\mathrm{R}^{\prime} / \mathrm{O} \mathrm{C}^{\prime}=z / T$.

Curve sheet 2 gives at once the values of $A$, and curve sheet 10 , the corresponding $A_{\mathrm{m}}$. The values so calculated for $Y_{\mathrm{m}}=$ 130 only; are given on curve sheet 11 .

An example best shows the use of these curves: Suppose

Schedule speed $=16.5 \mathrm{mph}$.

Distance between. stops $=2,000$ feet.

Time of stop $=15$ secs.

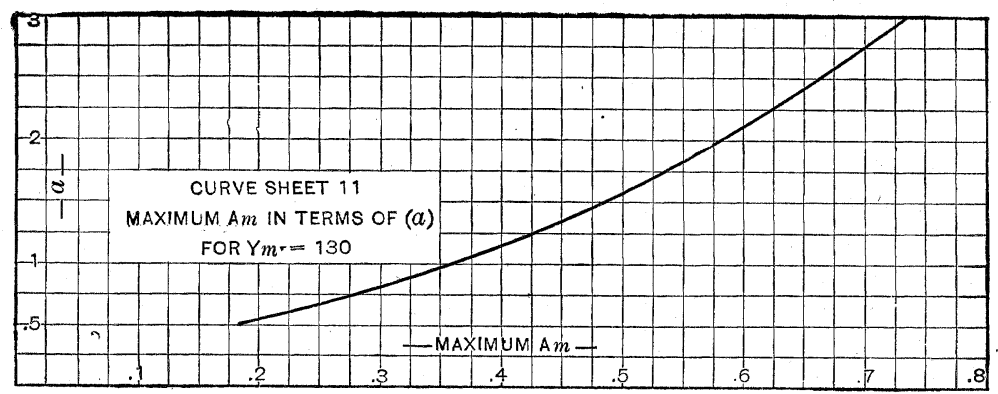

Then,

Total time from start to start $=82.4$ secs.

Running time $=67.4$ secs.

Average velocity, $V=20.2 \mathrm{mph}$.

$$
A=V / T=.3
$$

Curve sheet 11 shows that (a) must be greater than .75 ; take $a=1$; then curve sheet 8 determines the velocity curve up to the point $N$ (Fig. 4); for $Y_{\mathrm{m}}=130$, curve sheet 10 gives $A=$ .305 and from curve sheet 2 ,

$$
\begin{gathered}
x / T=.477 \\
y / T=.130 \\
z / T=.393
\end{gathered}
$$

Maximum velocity on type curve $=.477 \times 67.4=32.3 \mathrm{mph}$ 
Maximum velocity on motor curve $=32.2 \times 130 / 136=30.7$ mph. Velocity at braking $=3 \times .130 \times 67.4=26.3 \mathrm{mph}$.

Energy Input.-The energy at the car axle has already been determined; the electric input depends upon the method of motor control and the efficiency of the motor. I assume that series-parallel control in two steps is used. The power at the axle

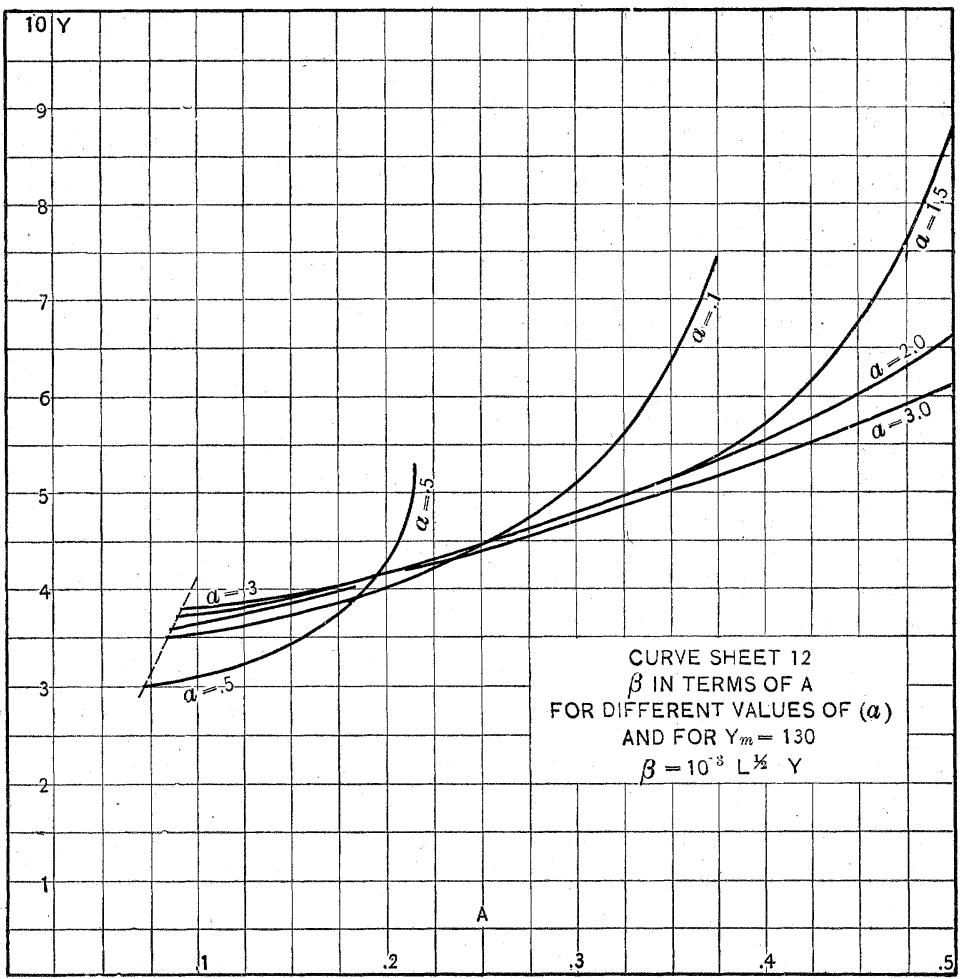

at rated velocity, that is, point $M$, is then $0.85 P_{0}$, where $P_{0}$ is the rated power, and the power at the axle is proportional to the speed. The change from series to parallel is assumed to occur at hall speed; the efficiency of the motors will be about $70 \%$ when in series and carrying rated current. With these figures the input up to $y=\beta 100$ is

and the output is

$$
W_{0}=.8 P_{0} t_{1}
$$

$$
W^{\prime}=.425 P_{0} t_{1}
$$


hence the efficiency up to rated velocity-while resistance is in circuit-is $53 \%$.

Substituting for $P_{0}$ its value from equation (23), and $t_{1}=$ $100 / \beta$, the input of electric energy per ton up to the point $M$ is

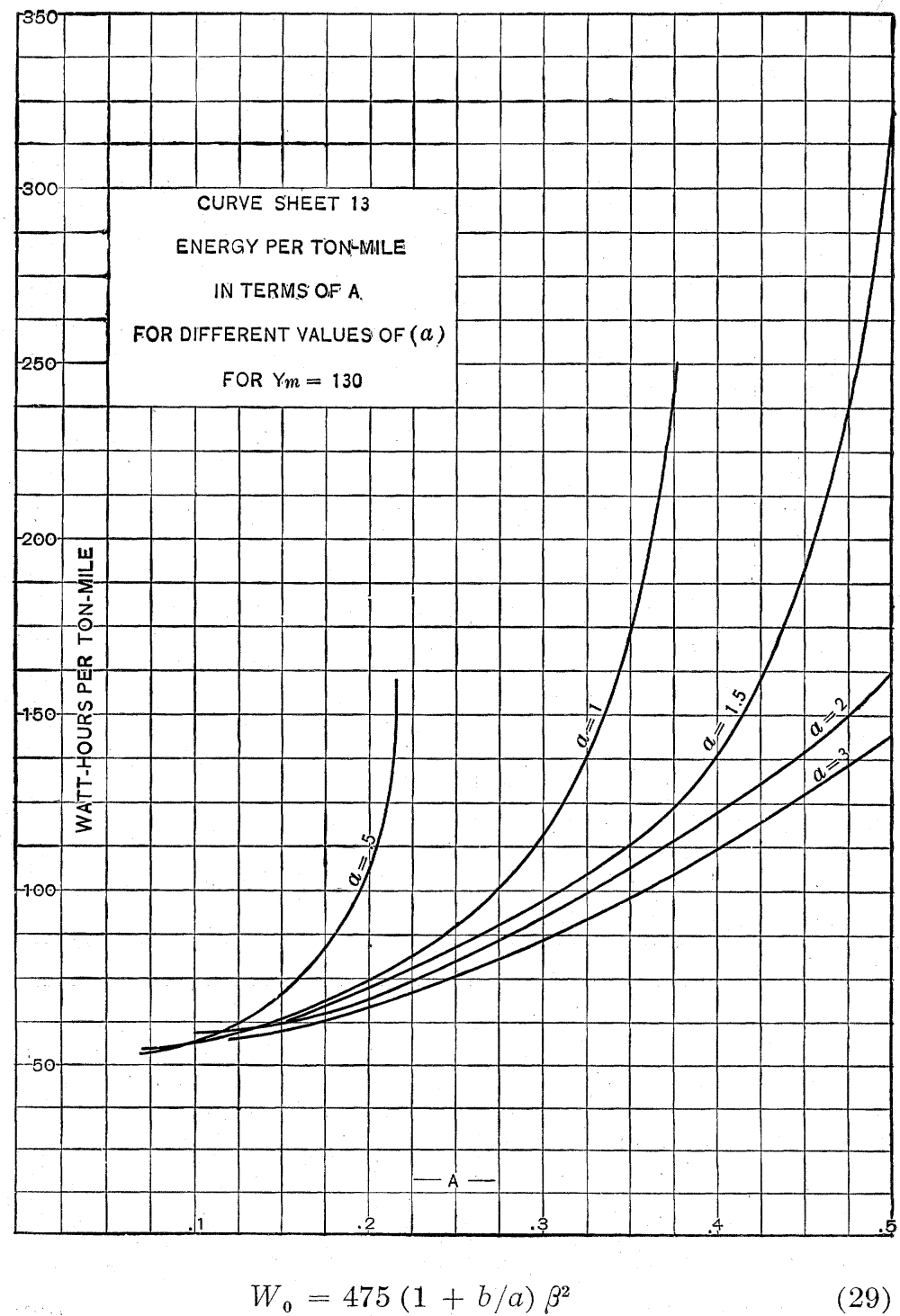

The values calculated from this equation are included on curve sheets $6,7,8$ and 9 , giving the energy up to the point $v=\beta 100$. 
The input from the point $M$ to the point $N$ on the motor curve, is taken directly from curve sheets 6 et seq. depending upon the initial acceleration.

Velocity Constant, $\beta$.-Energy, power and distance all involve the velocity constant $\beta$. The values of $\beta$ can be expressed in terms of the distance traversed, for all values of the through acceleration, as follows:

and

$$
\begin{aligned}
.682 L & =A T^{2} \\
T & =\beta X
\end{aligned}
$$

hence

$$
\beta=\left(\frac{.682 L}{A}\right)^{1 / 2} \times\left(\lambda / Y_{t}\right)=\left(\frac{.682 L}{A}\right)^{1 / 2} \frac{a}{Y_{t}} \frac{x}{T}
$$

The energy used is proportional to the product of $\beta^{2}$. by the ordinates of the energy curves on sheets 6 et seq. There will, therefore, be a different multiplier for each value of $(a)$ and of $Y_{\mathrm{m}}$.

Limiting the discussion to $Y_{\mathrm{m}}=100$ and $Y_{\mathrm{m}}=130$, the following table gives the values of the energy per ton in terms of $\beta$.

\begin{tabular}{|c|c|c|}
\hline (a) & $v=\beta 100$ & $v=\beta 130$ \\
\hline .5 & $665 \beta^{2}$ & $1115 \beta^{2}$ \\
\hline 1. & $570 ،$ & $865 “$ \\
\hline 1.5 & $535 “$ & 800 “ \\
\hline 2 . & $522 “$ & $767 ،$ \\
\hline 3. & $507 " ،$ & 732 “ \\
\hline
\end{tabular}

TABLE I.

Energy up to $v=\beta 100$ and $v=\beta 130$

From equation $30, \beta$ can be calculated for all values of $A$ and (a), and for all values of $Y_{\mathrm{m}}$. The simplest way to calculate these values is, first to assume values of $A$ and $(a)$; then since $Y_{\mathrm{m}}=130, Y_{\mathrm{t}}$ is fixed. The value of $x / T$ is taken from curve sheet 2 . 
$\beta$ is proportional to $L^{1 / 2} ; \beta^{2}$ to $L$; hence the energy used is proportional to the distance for any given value of $A$. The values of $\beta$ have been calculated from this equation for all values of $Y_{\mathrm{m}}$; I give here, however, a curve sheet showing these values

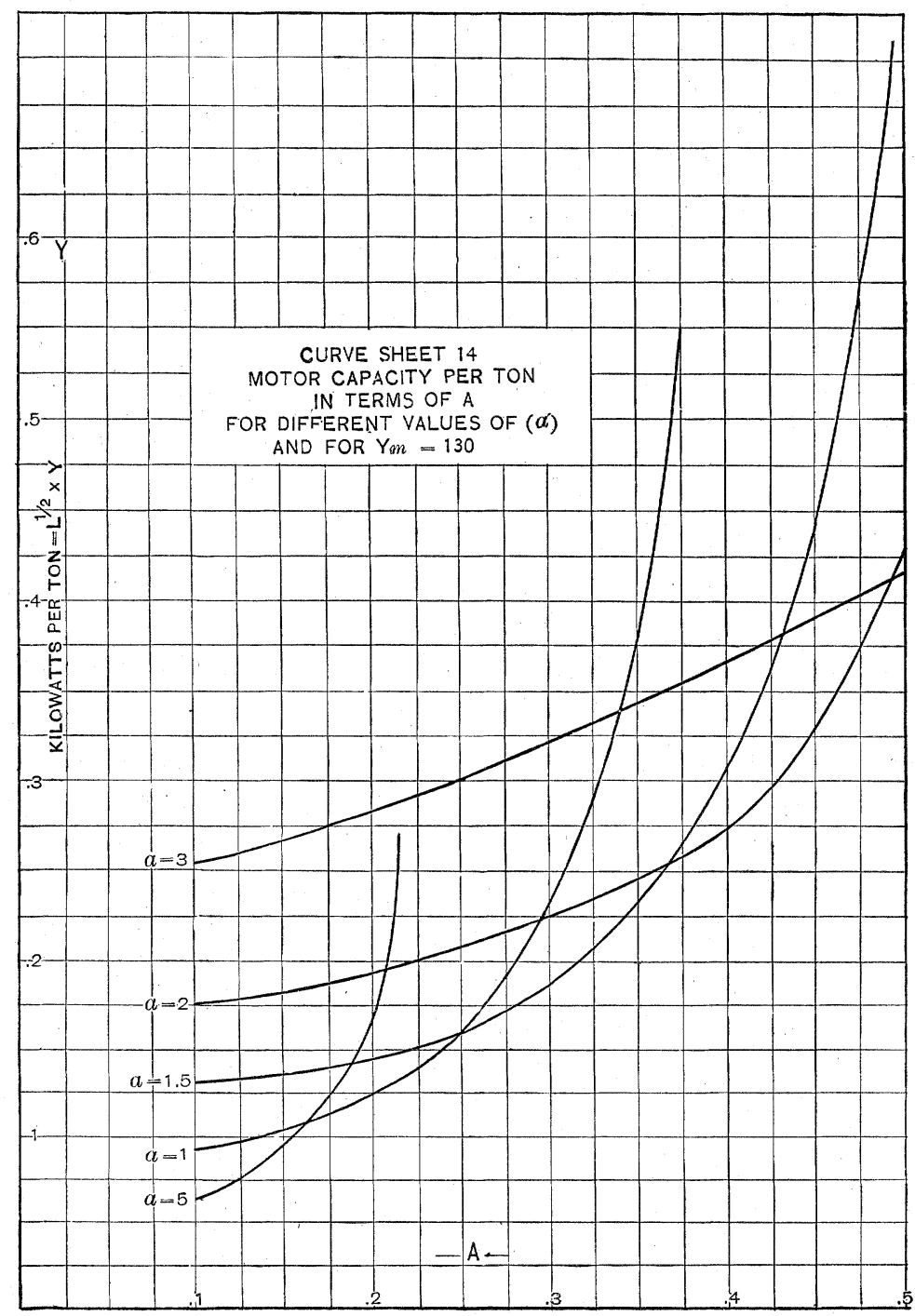

only for $Y_{\mathrm{m}}=130$, for the reason explained below.

This sheet covers the entire range of values of $\beta$ for $Y_{\mathrm{m}}=130$, from the minimum to $A=.5$; this value of $A$ is greater than is possible in practice. 
The energy for all schedules can now be calculated by multiplying $\beta^{2}$ from curve sheet 12 by the constants given in Table 1 . The values so calculated for $Y_{\mathrm{m}}=130$, are plotted on curve sheet 13 .

I have calculated the energy consumption in this manner for all values of $Y_{\mathrm{m}}$, and for the different values of $(a)$ and of $A$, up to $Y_{\mathbf{m}}=160$. To give all these results is of no value, since the result shows that in nearly all practical cases the energy input is substantially a minimum for $Y_{\mathrm{m}}=130$. Table 2 below shows the relative energy for different values of $Y_{\mathrm{m}}$ for $(a)=2$, in terms of energy for $Y_{\mathrm{m}}$, $=130$ as $100 \%$, for the various values of $A$.

\section{TABLE 2.}

Relative Energy for Different Use of Motor Curve for $(a)=2$ in Terms of Energy for $Y_{\mathrm{m}}=130$ as $100 \%$.

\begin{tabular}{l|l|l|l|l|l}
\hline & \multicolumn{3}{|c|}{$A$} \\
\hline & .5 & 4 & .3 & .2 & .1 \\
\hline 160 & - & $102 \%$ & $97 \%$ & $91 \%$ & $89 \%$ \\
150 & $104 \%$ & 101.5 & 98 & 93 & 93 \\
140 & 100 & 100 & 99 & 95.5 & 95 \\
130 & 100 & 100 & 100 & 100 & 100 \\
120 & 103.5 & 106.5 & 106.5 & 105.5 & 105 \\
110 & 110 & 112.5 & 113 & 112 & 108 \\
100 & 119 & 122 & 121 & 128 & 120 \\
\hline
\end{tabular}

This table is a fair example; it shows that the difference between the energy for 130 and greater values of $Y_{\mathrm{m}}$ is comparatively small. In the rest of this discussion, I use this value of $Y_{\mathrm{m}}$ only, and the values of $\beta$ are for this reason given only for $Y_{\mathrm{m}}=130$.

Curve sheet 13 gives at once the answer to all questions regarding the energy required for any schedule; it shows clearly how slight is the saving in energy effected by the use of rapid accelerations. For instance, for $A=.25$, the energy for an acceleration of one mile per hour per second is $17.2 \mathrm{wh}$; for an acceleration of $3 \mathrm{mph}$. / $\mathrm{sec}$, it is $14.5 \mathrm{wh}$; that is, increasing the 
acceleration in the ratio of three to one diminishes the energy required only $16 \%$.

Motor Capacity.-This discussion has been based throughout on the assumption that the motor operates at the rated capacity on the one-hour basis, when at the point $M$ (Fig. 4). On this assumption, the following table gives the capacity of the equipment required.

TABLE 3 .

\begin{tabular}{|c|c|}
\hline (a) & $P_{0}=\beta X$ \\
\hline .5 & $14.9 \mathrm{kw} /$ ton \\
\hline 1. & 25.5 \\
\hline 1.5 & 36.3 \\
\hline 2 . & 47. \\
\hline 3 . & 68. \\
\hline
\end{tabular}

These are the starting values of the power curves on sheets 6 , 7,8 and 9 , and may be considered the rated capacity of motors required, in so far as this rating is determined by commutation. Taking into account grades and curves and the possibility of various emergency requirements, I think it conservative to say that a motor should not be designed to operate above its one-hour capacity under the conditions here assumed; that is, on straight, level track, with frequent stops. The capacity of the motor depends also upon heating, and in most cases this is the ruling consideration. Hence it becomes necessary to determine the amount of heat liberated in the motor under all conditions of initial and through acceleration.

Heat Losses.- - Referring to Fig. 4, the heat losses in the copper up to the point $M$ are directly proportional to the time, since heat is liberated at a constant rate. The magnetic flux density in the motor is constant up to this point; if the core loss were proportional to the speed, the average loss would be one-half of the loss at rated speed; on the other hand, if the core loss were proportional to the square of the speed, the average loss would be one-third of the loss at rated speed; hence the average core loss 


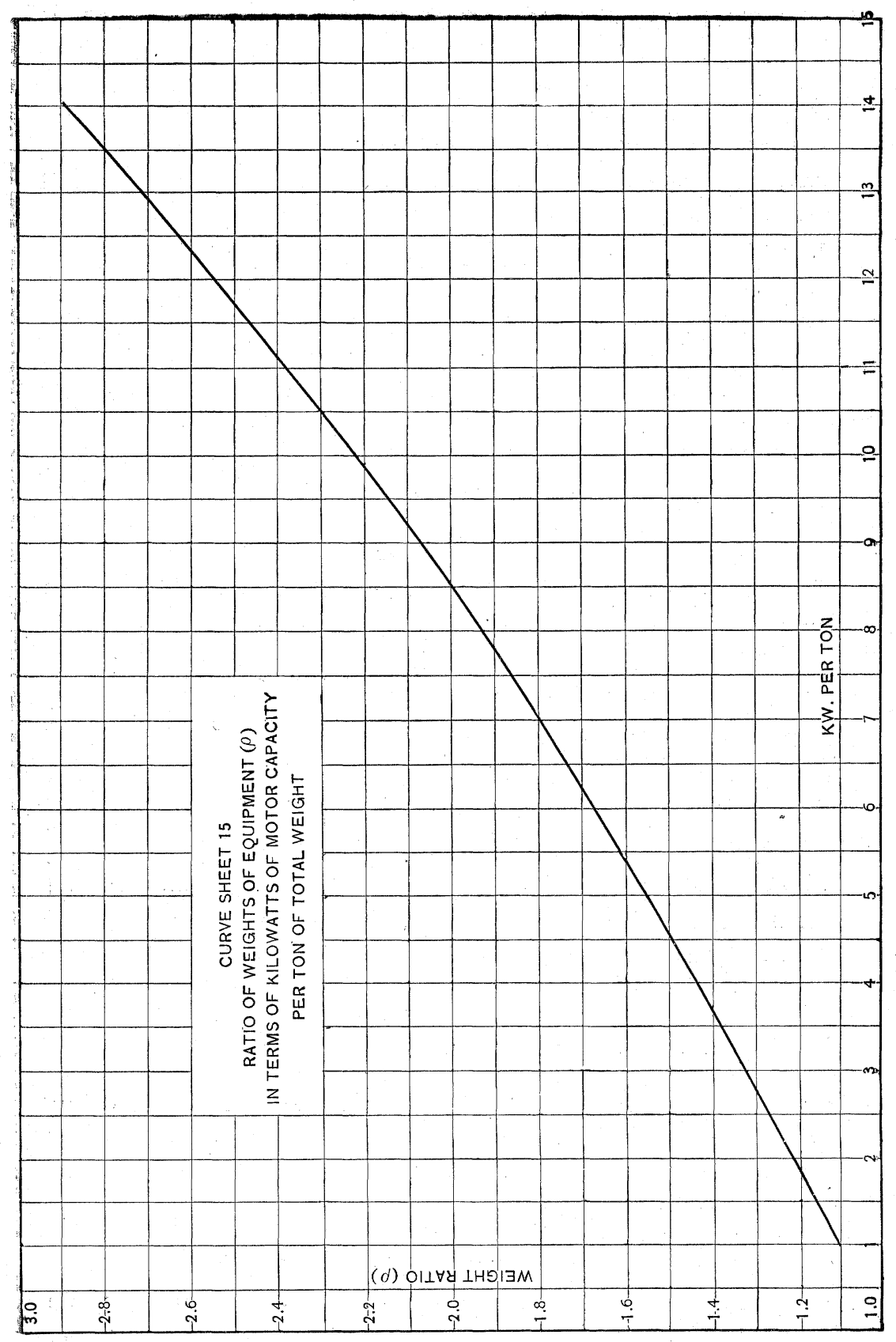


up to the point $\mathrm{o} \mathrm{m}$ is between 33 and 50 per cent. of this loss at rated speed. The actual variation of the core loss with.speed lies between these two values; I assume it to be equal to $41.0 \%$ of the loss at rated speed. It is of comparatively little consequence whether it be taken at 33 or $50 \%$ or at any intermediate value, since the core loss at rated speed is less than $30 \%$ of the total heat loss at rated speed; considerable errors in its values are of little moment.

I find from an examination of a number of modern tramway motors that at rated output $P_{0}$ the average core loss is $3.4 \%$, and the average copper loss $8.6 \%$ - a total for the average loss of $12 \%$, excluding friction losses. These losses are the average of a somewhat different group of motors from those used in preparing the general motor curve, hence the small loss left for friction; for this last group the efficiency is $83 \%$ instead of $85 \%$. The variations of the separate losses in the different motors is, generally speaking, small, although in certain motors the disparity is greater. The average loss up to $v=\beta 100$ is then $10 \%$ of the rated capacity, and is independent of initial acceleration.

From $M$ to $N$ on the motor curve, I have determined the losses: from curves of separate losses; for the same group of motors the average of the total heat loss from $v=\beta 100$ to $v=\beta 130$ is: $8.5 \%$ of the rated capacity.

Up to $v=\beta 100$, the average loss is $10 \%$ of $P_{0}$; for $v=\beta 130$, the values of $t_{1}$ and $t_{2}$ are taken from sheets $6,7,8$ and 9 , and the average loss over the total time $\left(t_{1}+t_{2}\right)$ calculated; it will be found to be constant for all values of $(a)$, as it should be, and equal to $9.4 \%$ of rated capacity.

The average rate of heat dissipation will be:

$$
\begin{array}{r}
.1 P_{0}, \text { up to } v=\beta 100 \\
\text { and } .094 P_{0}^{\prime} \text {, up to } v=\beta 130
\end{array}
$$

The rates continue for the times $t_{1}$ and $\left(t_{1}+t_{2}\right)$, respectively; during the rest of the cycle the motors are radiating heat; hence these rates referred to the total time $T$, are

$$
\begin{array}{r}
.1 t_{1} / T \times P_{0}, \text { up to } v=\beta 100 \\
.094\left(t_{1}+t_{2}\right) / T \times P^{\prime} \text {, up to } v=\beta 130,
\end{array}
$$

and as percentages of the rated capacities in the two cases; are

$$
\begin{array}{ll}
10 t_{1} / T \% & \text { up to } v=\beta 100 \\
9.4 \times\left(t_{1}+t_{2}\right) / T \% & \text { up to } v=\beta 130
\end{array}
$$


These are the average rates for the entire time from start to stop, and by comparison with the average loss that such a motor will stand continuously without excessive heating, determine whether the motors would be running above or below their rated capacity; or conversely, determine what the capacity on a onehour basis must be, so that when operating in this way they will not over-heat.

Equation (32) can be written

But (Fig. 4)

$$
9.4\left(1+t_{2} / t_{1}\right) t_{1} / T \%
$$

$$
\begin{aligned}
t_{1} & =\overline{\mathrm{OP}}=O \mathrm{D} . \mathrm{MP} / \mathrm{AD} \\
& =x \times 100 / Y
\end{aligned}
$$$$
\text { and } t_{1} / T=x / T(100 / Y)
$$

hence the total heat loss up to the velocity $\beta 130$ averaged over the entire time $T$ is

$$
9.4\left(1+t_{2} / t_{1}\right) \times 100 / Y \times x / T \%
$$

where $x / T$ is taken from curve sheet 2 for the proper values of $A$ and $(a)$. In this deduction it is assumed that $A_{\mathrm{m}}=A$.

Hour Rating. - The one-hour rating of a tramway motor is much in excess of the continuous capacity; approximately such a motor will carry its rated output for $25 \%$ of the total time, that is, for one minute out of four; the heat generated at rated capacity for one-quarter of a complete cycle will bring it to its rated temperature. It is assumed that the cycles are repeated at such intervals that a permanent regime is attained. This is only an approximation, but is a fair one, if the percentage be more or less than 25 , and the conclusions can be altered to accord.

As the average heat losses at rated load are $12 \%$, it follows that such a motor can dissipate continuously $3 \%$ of its rated capacity; when the average rate is over $3 \%$ the motor is overloaded.

Since the average loss that a motor will stand is equal to $3 \%$, it follows that the maximum value of $(x / T)$, or $(x / T)_{0}$ is

$$
(x / T)_{0}=3 /\left[9.4\left(1+t_{2} / t_{1}\right)\right] \times Y / 100
$$

Curve sheets $6,7,8$ and 9 give then 
TABLE 4.

\begin{tabular}{|c|c|}
\hline$(a)$ & $(x / T)_{\circ}$ \\
\hline .5 & 0.249 \\
1. & 0.260 \\
1.5 & 0.265 \\
2. & 0.270 \\
3 & 0.271 \\
\hline
\end{tabular}

For $Y_{\mathrm{t}}=100$, the limiting value is $(x / T)_{0}=.3$, for all values of $A$ and (a).

This means that for schedules in which $x / T>.3$, in one case, and for $x / T>.249$ et seq. in the other, the capacity must be greater than the capacity determined by commutation; that is, greater than the values of Table 3 in the ratio of $(x / T) /(x / T)_{0}$; for $x / T>.3$, or less than the values of Table 4 , commutation determines the capacity.

The motor capacity necessary both to avoid overheating and to keep within commutation limits, can now be calculated from these data. Table 3 gives the capacity required on the assumption that commutation is the only limit to output, and on the further assumption that the hourly rated capacity is the practical limit determined by commutation. These values, multiplied by the ratio $(x / T) /(x / T)$, give the capacity in all cases, with the limitation that the capacity shall not be less than that of Table 3 . Then,

$$
\text { Motor capacity }=14.9 \beta \times(x / T) /(x / T)_{0} \text { for } a=.5
$$
and,

$$
\text { Motor capacity }>14.9 \beta \text { for } a=.5
$$

The coefficient for other values of the initial acceleration is given by Table 4 .

The capacity of the motor, as determined by this equation, has been calculated for all values of $A$ and $(a)$, and curve sheet 14 gives the kilowatts per ton, considering both commutation and heating, for $Y_{\mathrm{m}}=130$.

For the lowest acceleration $(a)=.5$, heating is the limitation for all values of $A$; for the higher values of $(a)$, commutation is the limitation for the low, and heating for the high, values of $A$.

I wish to emphasize the conditions under which these capacity 
curves were obtained; (1) that the limit of input determined by commutation is the rated capacity, and (2) that the limit determined by heating is an input that will average for the total time $3 \%$ of rated capacity in copper and core losses. I am aware that motors are operated at much greater inputs than the rated capacity in regular service, but for service requiring frequent stops this is not unduly low, if low maintenance cost is taken into account. It is easy to follow out this argument with any desired overload at starting; the results will be but slightly affected.

Similarly, with reference to heating, $3 \%$ is not a sacred figure, but only a fair average; it is easy to make the changes for any other value. No changes within practical limitations will affect the relative results for different schedules and initial accelerations; the absolute values only will be slightly changed.

As this entire discussion has been based on the assumption that the input of the motor along the line o $\mathrm{m}$ of Fig. 4 (that is, during the period of constant acceleration) is its rated capacity, it would seem at first glance, that the increase of capacity necessitated by heating conditions, would vitiate all the deductions given here. This however, is not the case. The velocities are in no way affected; hence the energy at the car axle is unaltered. The only change brought about by using a motor that does not operate at its rated capacity during the initial period, is a change in the heat losses in the motor. This will not affect the energy input greeatly, since almost the entire losses during this period are losses in external resistance; hence, the curves showing energy required per ton mile will be substantially unaltered. Such change will in all cases increase the heat waste in the motor, hence the capacity, given on curve sheet 14, will in all cases be somewhat too small. On the other hand, the capacity so calculated is greater than necessary, as no allowance has been made for heat radiation during the time of stop at stations.

Another consideration leads to the same result. As I have shown, the energy used per ton mile varies very slightly for any amount of acceleration on the motor curve from $120 \%$ to $160 \%$. To use a motor at other than the rated capacity means that the motor is operating on a different part of the motor curve; hence the difference in energy input will be small.

Weight of Equipment.-These curve sheets show that the motor capacity for high initial accelerations is generally greatly in excess of the motor capacity required for low initial accelerations. Greater capacity of equipment necessarily means 
greater weight of equipment, not only in the motors themselves, but also in the trucks, controllers and other parts. This entails the further necessity of more energy to carry this greater weight; each addition of weight means a further addition to the energy necessary. To get a correct comparison of the total energy per mile required for different initial accelerations, the values of curve sheet 13 should be multiplied by the ratio of the necessary weights in the two cases. For instance, for an initial acceleration of $3 \mathrm{mph}$. $/ \mathrm{sec}$, the total weight of equipment may be $25 \%$ greater than for an initial acceleration of $1 \mathrm{mph} . / \mathrm{sec}$; t the total energy used per mile will then be increased in the ratio of increase of the weights.

I have taken the weights of all parts of a car equipment in detail for different capacity of motors, varying from 30 to 150 rated H.P., for both two and four motor equipments. These weights include motors, controllers, trolley poles, car wiring, motor trucks, trail trucks and car body. I have deduced from these weights, curve sheet 15 , on which the ordinates show the ratio of weights for different capacity of equipment, in terms of $\mathrm{kw}$./ton of total weight as abscissæ. For instance, for an equipment of $4 \mathrm{kw}$./ton of total weight, the ratio is 1.44 ; for an equipment of $8 \mathrm{kw}$./ton, the ratio is 1.93 ; the increase of equipment from 4 to $8 \mathrm{kw}$./ton then increases the total weight in the ratio of $1.93 / 1.44=1.34$; that is, doubling the equipment means an increase of $34 \%$ in total weight; hence, $34 \%$ in total energy used. The ordinates of curve sheet 13 giving energy per ton mile, multiplied by the ratios from curve sheet 15 for the different capacity of equipments, determined by curve sheet 14 , will be proportional to the total energy required per mile.

The capacity of the equipment is proportional to $L^{1 / 2}$ and as the distance will vary in each case, it is not possible to deduce any general results; each case must be considered by itself, in this particular. I have made these calculations for a number of cases to correspond with practical conditions; the result is always that the energy used per mile is less for the lower acceleration. As an example:

Let

$$
\begin{aligned}
& V=16.5 \mathrm{mph} . \\
& L=2,000 \text { feet. }
\end{aligned}
$$

then

$$
A=.2
$$


From the various curve sheets, the following table is deduced:

TABLE 5 .

\begin{tabular}{|c|c|c|c|c|c|}
\hline \multirow{2}{*}{$a$} & \multirow{2}{*}{$\mathrm{kw} /$ ton } & \multirow{2}{*}{ wh./ton } & \multirow{2}{*}{$\rho$} & \multicolumn{2}{|c|}{$\rho \times$ wh./ton. } \\
\hline & & & & wh & $\%$ \\
\hline .5 & 7.6 & 106 & 1.87 & 198 & 174 \\
\hline 1. & 5.6 & 75 & 1.63 & 114 & 100 \\
\hline 1.5 & 6.5 & 73 & 1.73 & 126 & 111 \\
\hline 2.0 & 8.7 & 70 & 2.03 & 142 & 124 \\
\hline 3.0 & 12.6 & 67 & 2.65 & 177 & $156^{\circ}$ \\
\hline
\end{tabular}

The last column of this table shows the energy required per mile to be the minimum for an acceleration of $1 \mathrm{mph}$./sec.; the motor capacity is also at a minimum for this acceleration.

To take the case of the proposed express service of the New York Rapid Transit Line: here the schedule speed will be 35 $\mathrm{mph}$; the average distance between stations, about 7,500 feet; time of stop at stations, 15 seconds.

From these data,

$$
\begin{aligned}
& V=38.8 \mathrm{mph} . \\
& \text { and } A=.275
\end{aligned}
$$

The following table is deduced from these data:

TABLE 6 .

\begin{tabular}{l|c|c}
\hline$a$ & $\mathrm{kw} . /$ ton & wh./ton. \\
\hline 1. & 16.7 & 102 \\
1.5 & 14.9 & 82 \\
2. & 18.8 & 72 \\
3. & 26.9 & 62 \\
\hline
\end{tabular}

This table shows the practical impossibility of accomplishing such a schedule on the assumptions of this discussion. The 
minimum motor capacity required of $14.9 \mathrm{kw}$./ton, is beyond the range of practical conditions. The weight of motors, controllers and wiring, that is, the electrical equipment alone, will be about 75 pounds per kilowatt, and the weight for $14.9 \mathrm{k} . \mathrm{w}$ would be about 1,140 pounds. This does not leave sufficient weight for the other parts of the equipment. For an acceleration of $3 \mathrm{mph}$./sec., the weight of the motors required, $26.9 \mathrm{kw}$., would be approximately one ton; that is to say, at this initial acceleration, the motors would just be able to propel themselves.

Conclusions.- $\mathrm{My}$ conclusion from this discussion is that the acceleration that gives the lowest motor capacity per ton is generally the most economical. The very small saving in energy is not to be compared with the many disadvantages of very rapid initial acceleration. Assume, for instance, a gain of 10 watt-hours per ton mile for an acceleration of 3 , over that required for an acceleration of 1 ; for a 20 -ton car, and with energy at .5 cents per $\mathrm{kw}$. hour, this represents a saving of .1 cent per car mile. This is too trifling to be considered in comparison with the fixed charges on the greater investment for motors and distribution system; the poorer load factor at the power station, the increased cost of maintenance, the difficulty of accurate handling of cars, and, above all, the much greater discomfort to passengers.

Although I have had to make in the course of this discussion, various more or less arbitrary assumptions, I believe that they are all fair ones, representing average conditions. It is open to any one to follow this method on such other assumptions as may suit his fancy. I believe, however, that no practical assumptions will change the general results. 